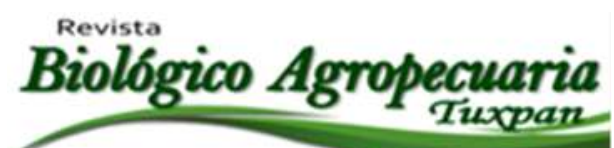

\title{
Efecto de la vacunación a IBR con virus vivo y muerto, sobre las características anatómicas y endocrinológicas del cuerpo lúteo en novillas Holstein mestizas
}

Effect of IBR vaccination with live and dead virus on the anatomical and endocrinologic characteristics of the corpus luteum in mixed Holstein heifers

\author{
Castro Guamán W. E. ${ }^{1}$, Maldonado Rivera, J. E. C. ${ }^{2}$, y Marini, P. R. ${ }^{3 凶}$ Elorza, P. ${ }^{4}$ Daniel-Rentería, I. ${ }^{4}$ \\ ${ }^{1}$ Actividad privada. Amazonia - Ecuador. \\ ${ }^{2}$ Facultad de Ciencias Agropecuarias, Universidad de Cuenca, Ecuador. \\ ${ }^{3}$ Facultad de Ciencias Veterinarias-Universidad Nacional de Rosario - Argentina. \\ ${ }^{4}$ Facultad de Ciencias Biológicas y Agropecuarias, Universidad Veracruzana, México. \\ ${ }^{\otimes}$ Autor para correspondencia: pmarini@unr.edu.ar
}

Recibido: $12 / 03 / 2018$

Aceptado: 14/05/2018

\section{RESUMEN}

El presente estudio se realizó para determinar si la vacunación con el herpes virus bovino tipo 1(HVB-1) como profilaxis para la rinotraqueitis infecciosa bovina tiene efecto sobre las características anatómicas y endocrinológicas del cuerpo lúteo en novillas Holstein mestizas en la región amazónica ecuatoriana. Se utilizaron 60 novillas repartidas en tres grupos de 20 animales cada uno: sin inmunógeno, vacuna a virus vivo y vacuna a virus muerto. Se determinó el diámetro del cuerpo lúteo en diferentes estadios (12 y 18 días posinseminación) de desarrollo mediante ultrasonografía trans-rectal y la concentración de la progesterona en la sangre, por inmunoensayo enzimático. Para el manejo del experimento todos los grupos fueron sometidos a un protocolo de sincronización con prosgestágenos y estradiol. Se observó diferencias estadísticas significativas en el diámetro promedio del cuerpo lúteo a los 12 y 18 días, siendo mayor en el tratamiento testigo (26,5 y 29,9 mm) respectivamente seguido del tratamiento con virus vivo con (19,5 y 17,9 mm) y el tratamiento con virus muerto con $(19,2 \mathrm{~mm}$ y $17,9 \mathrm{~mm})$. La concentración sanguínea de progesterona fue estadísticamente mayor a los 12 y 18 días post-tratamiento en el tratamiento testigo $(5,1$ y $5,7 \mathrm{ng} / \mathrm{dl})$ seguido por el tratamiento con virus vivo $(3,2$ y $2,8 \mathrm{ng} / \mathrm{dl})$ y el tratamiento con virus muerto $(3,1$ y $2,8 \mathrm{ng} / \mathrm{dl})$ donde hubo valores estadísticamente diferentes en los tres tratamientos en estudio. La inoculación con el herpes virus bovino tipo 1 tiene efectos sobre el desarrollo temprano del cuerpo lúteo en novillas y la concentración de progesterona sanguínea.

Palabras clave: Cuerpo Lúteo, Progesterona, IBR, Ecógrafo, Vacunas Vivos Y Muertos.

\begin{abstract}
ABSTRAC
The present study was conducted to determine whether vaccination with bovine herpes virus type 1 (HVB-1) as prophylaxis for infectious bovine rhinotracheitis has an effect on the anatomical and endocrinologic characteristics of the corpus luteum in mixed Holstein heifers in the Ecuadorian Amazon region. Sixty heifers divided into three groups of 20 animals each were used: no immunogen, live virus vaccine and killed virus vaccine. The diameter of the corpus luteum was determined in different stages (12 and 18 days post-dissemination) by transrectal ultrasonography and the concentration of progesterone in the blood, by enzyme immunoassay. For the management of the experiment, all the groups were subjected to a synchronization protocol
\end{abstract}


with prostaglandins and estradiol. Significant statistical differences were observed in the average diameter of the corpus luteum at 12 and 18 days, being higher in the control treatment $(26,5$ and $29,9 \mathrm{~mm})$ respectively followed by treatment with live virus with $(19,5$ and 17, $9 \mathrm{~mm})$ and the treatment with dead virus $(19,2 \mathrm{~mm}$ and $17,9 \mathrm{~mm})$. The blood concentration of progesterone was statistically higher at 12 and 18 days post-treatment in the control treatment (5,1 and 5,7 ng / dl) followed by treatment with live virus $(3,2$ and 2,8 $\mathrm{ng} / \mathrm{dl})$ and treatment with dead virus $(3,1$ and $2,8 \mathrm{ng} / \mathrm{dl}$ ) where there were statistically different values in the three treatments under study. Inoculation with bovine herpes virus type 1 has effects on the early development of the corpus luteum in heifers and the concentration of blood progesterone.

Key Words: Corpus luteum, progesterone, IBR, ultrasound, vaccines alive and death.

\section{INTRODUCCIÓN}

La Rinotraqueitis Infecciosa Bovina (IBR), es una patología viral infectocontagiosa, el virus puede permanecer en estado latente dentro de los ganglios nerviosos y reactivarse por diversas situaciones que provoquen stress como el trasporte, parto y tratamientos con glucocorticoides ocasionando una reducción de la eficiencia reproductiva al producir abortos, lesiones necróticas en estructuras foliculares, lúteales, muerte embrionaria , neonatal, pérdida de peso y disminución de la producción láctea (Etchegaray, 2009).

En el contexto ganadero de la Amazonía Ecuatoriana, la falta de programas de control y profilaxis para las enfermedades virales se convierte en un entorno predisponente para la incidencia y prevalencia de enfermedades como el IBR.

Actualmente se acepta que el VHB-1 es un agente potencial de aborto en el bovino asociado directamente con la forma respiratoria y conjuntival, excluyéndose toda relación con vulvovaginitis pustular infecciosa (Mars et al., 2000). Estudios experimentales previos demostraron de la posibilidad de que la infección por VHB-1 tenga un efecto negativo sobre la fertilidad (Raaperi et al., 2012). Nardelli et al., (2008) concluyeron en un trabajo en novillas que las lesiones son fácilmente inducidas en los ovarios en el post-estro como resultado de la diseminación hematógena del virus de la IBR.

Por otro lado, Biuk-Rudan et al., (2000) inocularon seis novillas en el celo con el virus de la rinotraqueitis bovina infecciosa y las mediciones progesterona plasmática indicaron que la función del cuerpo lúteo estaba deprimida en todas las vaquillas.

El objetivo de este trabajo fue evaluar el efecto de la vacunación de IBR con vacunas a virus vivo y muerto sobre las características anatómicas y endocrinológicas del cuerpo lúteo de novillas Holstein mestizas.

\section{MATERIALES Y MÉTODOS}

El trabajo se realizó en el Cantón Santa Clara Provincia de Pastaza en la Amazonia Ecuatoriana, se utilizaron 60 vaquillas Holstein mestizas, los animales estaban sexualmente maduros (chequeado a través de ecografía) y clínicamente sanos, con un peso mínimo de $350 \mathrm{Kg}$, en una edad entre 18 y 24 meses, que hayan vivido por lo menos un año en el trópico, con una Condición Corporal entre 2,75 y 3,5, además vacunados para fiebre aftosa, rabia y carbunco. Se conformaron tres grupos: sin vacunación grupo testigo (T) 20 vaquillas, vacunados con virus vivo (cattlemaster) (VV) 20 
vaquillas $\mathrm{y}$ vacunados con virus muerto (hiprabovis-4) (VM) 20 vaquillas. En esta etapa los animales fueron sometidos a un programa de sincronización, para que las vaquillas inicien de manera homogénea un nuevo ciclo estral, dentro del cual se puedo realizar el monitoreo respectivo. Para la sincronización se utilizó: Benzoato de estradiol en dosis de 0.5 cc por animal, y un dispositivo intravaginal CIDR de liberación lenta de Progesterona el día cero, siete días posteriores se realizó la aplicación de prostaglandina, retiro del implante de $\mathrm{P} 4$, inyección de estradiol dando inicio así a un nuevo ciclo estral, lo cual se estimó que la ovulación sea aproximadamente a las 60 hs pos tratamiento y de allí determinar los tiempos para los estudios posteriores del CL. La aplicación de la vacuna se lo realizó 60 horas post tratamiento de sincronización, la profilaxis vacunal respectiva fue con el virus vivo (cattlemaster) y muerto (hiprabovis-4), como se explicó anteriormente en el esquema del experimento. El monitoreo del tamaño del cuerpo lúteo se realizó por ultrasonografía y el procesamiento de las muestras de sangre se realizó en el Laboratorio clínico veterinario BIOMICROVET, Cuenca-Ecuador. Se realizaron dos mediciones: 1) al día $12^{\circ}$ después de la detección del celo de la vacunación, 2) al día $18^{\circ}$ después de la detección del celo de la vacunación. En cada medición se tomaron muestras de sangre para evaluar los niveles de P4. Se utilizó un Diseño de Completamente al Azar (DCA), los resultados fueron sometidos a la prueba de homogeneidad, para cada variable estudiada se estimaron la media aritmética y el error estándar (EE). Se probó si existían diferencias significativas entre los genotipos mediante la aplicación de análisis de la variancia (ANOVA) a un criterio de clasificación y pruebas de comparaciones múltiples de Tukey-Kramer HSD $(\mathrm{p} \leq 0,05)$.
Los análisis estadísticos fueron realizados utilizando el programa JMP (JMP®, 2003) en su versión 5.0 para Windows.

\section{RESULTADOS Y DISCUSIÓN}

El Cuadro 1 muestra la existencia de diferencias significativas $(p<0,05)$, del grupo testigo en referencia al tamaño del cuerpo lúteo y los niveles de progesterona con los tratamientos con virus vivo y virus muerto. No mostrando diferencias significativas $(p \geq 0,05)$ entre los tratamiento con virus vivo y virus muerto en el tamaño del cuerpo lúteo y los niveles de progesterona.

Los resultados coinciden Geiser et al., (2002) en donde mostraron en seis novillas inoculadas en el celo con el virus de la rinotraqueitis bovina infecciosa, que las mediciones de la progesterona plasmática indicaron que la función del cuerpo lúteo estaba deprimida en todas las vaquillas, en el primer ciclo estral después de la inoculación los valores de progesterona no excedieron 2 ng / dl. En este trabajo los valores encontrados fueron superiores en los tres tratamientos.

Woodbine et al., (2009) realizó un trabajo en novillas que fueron inoculados intravenosamente con virus de la rinotraqueitis bovina infecciosa a los días 7 , 14,21, y 28, y se sacrificaron 13 a 15 días después de la inoculación para luego examinar los tractos reproductivos para detectar cambios citopatológicos, virus y antígeno viral, en donde las novillas inoculadas en los días 7 y 14 presentaban ooforitis leve caracterizada por focos de necrosis y acumulación de células mononucleares en el cuerpo lúteo la mayoría 
de estas novillas también tenían algunos folículos necróticos en al menos un ovario, las novillas inoculadas en los días 21 y 28 no presentaban lesiones del cuerpo lúteo pero los folículos necróticos eran numerosos en ambos ovarios, el antígeno viral se observó en todas las lesiones ováricas y el virus infeccioso fue aislado de algunos de los tejidos afectados en útero de todas las novillas inoculadas a los 21 y 28 días.

\begin{tabular}{|lcccc|}
\hline $\begin{array}{l}\text { Cuadro1: Promedios y desvíos estándar del tamaño del cuerpo lúteo y niveles de progesterona } \\
\text { en los días } 12 \text { y } 18 \text { después de la detección de celos en los diferentes tratamientos }\end{array}$ \\
\hline \multicolumn{4}{c}{ Día 12} & \multicolumn{2}{c|}{ Día 18} \\
\hline $\begin{array}{c}\text { Cuerpo lúteo } \\
(\mathrm{mm})\end{array}$ & $\begin{array}{c}\text { Progesterona } \\
(\mathrm{ng} / \mathrm{dl})\end{array}$ & $\begin{array}{c}\text { Cuerpo lúteo } \\
(\mathrm{mm})\end{array}$ & $\begin{array}{c}\text { Progesterona } \\
(\mathrm{ng} / \mathrm{dl})\end{array}$ \\
\hline Testigo & $26,5 \pm 0,9 \mathrm{a}$ & $5,1 \pm 0,6 \mathrm{a}$ & $29,9 \pm 0,9 \mathrm{a}$ & $5,7 \pm 0,8 \mathrm{a}$ \\
\hline Virus Vivo & $19,5 \pm 1,0 \mathrm{~b}$ & $3,2 \pm 0,7 \mathrm{ab}$ & $17,9 \pm 1,0 \mathrm{~b}$ & $2,8 \pm 1,0 \mathrm{ab}$ \\
\hline Virus Muerto & $19,2 \pm 0,9 \mathrm{~b}$ & $3,1 \pm 0,6 \mathrm{~b}$ & $17,9 \pm 0,9 \mathrm{~b}$ & $2,8 \pm 0,8 \mathrm{~b}$ \\
\hline Letras diferentes en una misma columna indican diferencias significativas $\mathrm{p} \leq 0,05$ \\
\hline
\end{tabular}

\section{CONCLUSIONES}

Se concluye que las vacunas profilácticas del IBR con virus vivo y muerto podrían afectar las características anatómicas y endocrinológicas del cuerpo lúteo y por ende su comportamiento reproductivo.

\section{LITERATURA CITADA}

Biuk-Rudan N, S. C. (2000). Prevalence of antibodies to ibr and bvd viruses in dairy cows with reproductive disorders. el sevier, 63-70. Recuperado el 24 de 02 de 2017, de https://www.ncbi.nlm.nih.gov/pubmed/ 10729010.

Etchegaray1, P. B. (2009). Rinotraqueitis infecciosa bovina. Monografias de medicina veterinaria, 1-9. Recuperado el 15 de 06 de 2017, de http://www.fmvz.unam.mx/fmvz/cienci avet/revistas/CVvol1/CVv1c06.PDF.

Geiser V., I. M. (2002). The latency-related gene of bovine herpesvirus-1 can inhibit the ability of bICP0 to activate productive infection. Gen. Virol., 83:2965-2971.
Graham, D. A. (2013). Bovine herpes virus-1 (BoHV-1) in cattle-a review with emphasis on reproductive impacts and the emergence of infection in Ireland and the United Kingdom. Graham Irish Veterinary Journal, 66:15.

Mars, M. d. (2000). Airborne transmission of bovine herpesvirus 1 infections in calves under field conditions. Vet. Microbiol., 76, 1-13.

Raaperi K, B. S. (2012). Association of herd BRSV and BHV-1 seroprevalence with respiratory disease and reproductive performance in adult dairy cattle. Vet Scand, 54:4.

Woodbine KA, M. G.-V. (2009). A four-year longitudinal sero-epidemiological study of bovine herpesvirus type-1 (BHV-1) in adult cattle in 107 unvaccinated herds in south west England. Vet Res, 5:5. Recuperado el 12 de 05 de 2017, de

https://www.ncbi.nlm.nih.gov/pubmed/ 19183476. 


\title{
(9) (1)
}

Este tex to está protegido por una licencia licencia CreativeCommons 4.0

\begin{abstract}
Usted es libre para Compartir —copiar y redistribuir el material en cualquier medio o form ato- y Adaptar el documento $\rightarrow$ remezclar, transformar y crear a partir del material- para cualquier propósito, , incluso para fines comerciales, siempre que cumpla la condición de:

Atribución: Usted debe dar crédito a la obra original de manera adecuada, proporcionar un enlace a la licencia, e in dicar si se han realizado cam bios. Puede hacerlo en cualquier form a razonable, pero no de form a tal que sugiera que tiene el apoyo del licenciante o lo recibe por el uso que hace de la obra.
\end{abstract}

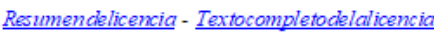

